[Aus dem Institut für Infectionskrankheiten in Berlin.]

(Director: Geh. Med.-Rath Prof. Dr. Gaffky.)

\title{
Weitere Mittheilungen über die Immunität gegen Streptokokken und Pneumokokken.
}

Von

Dr. F. Neufeld und Dr. W. Rimpau.

In einer früheren Viittheilung ${ }^{1}$ haben wir kurz über Versuche berichtet, die uns zu einer in wesentlichen Punkten neuen Auffassung über die der Immnnität gegen Strepto- und Pneumokokken zu Grunde liegenden Verhältnisse führten. Bekanntlich ist früher vielfach die Möglichkeit, ein gegen die genannten beiden Mikroorganismen gerichtetes Serum zu gewinnen, tuberhaupt bezweifelt worden; nachdem nunmehr die Thatsache eines im Thierversuch wirksamen Serums gesichert erscheint, ist über die Art der in dem Serum enthaltenen specifischen Stoffe eine Uebereinstimmung trotz vieler auf diesen Punkt gerichteten Untersuchungen nicht erzielt worden.

Was das Pneumokokkenserum anlangt, so haben G. u. F. Klemperer ${ }^{2}$, die als die ersten ein zweifellos specifisch wirksames Serum in Händen gehabt haben, angenommen, dass seine Wirkung auf einem Antitoxin beruht; nach ihnen haben sich Foà u. A., in allerjüngster Zeit noch Tizzoni and Panichi ${ }^{3}$ für diese Ansicht ausgesprochen; die letzteren Autoren nehmen ausserdem an, dass die Kokken in dem Körper des immunisirten Thieres eine dauernde Virulenzabschwächung erleiden. Dem

1 Deutsche med. Wochenschrift. 1904. Nr. 40.

2 Berliner klin. Wochenschrift. 1891.

3 Centralblatt für Bakteriologie. 1905. 
gegenüber haben eine Reihe anderer Autoren, vor Allem Emmerich ${ }^{1}$, ferner Bonome ${ }^{2}$ and in den letzten Jahren Römer ${ }^{3}$ das Serum als ein baktericides erklärt. Innen schliesst sich Weichselbaum in seiner im Jahre 1904 erschienenen Monographie ${ }^{4}$ an. .

Dagegen ist von Issaeff ${ }^{5}$ in einer in Ietschnik off's Laboratorium entstandenen Arbeit die Ansicht begründet worden, dass das Serum weder eine baktericide, noch eine antitoxische Wirkung besitzt, sondern dass es die Leukocyten derart stimulirt, dass sie die Infectionserreger durch Phagocytose vernichten. Diese Hypothese, der sich mehrere spätere Autoren anschlossen, ist durch Denys Schüler Mennes ${ }^{6}$ und durch Huber ${ }^{7}$, auf deren Versuche wir noch zurückkommen, aufgenommen und ergänzt worden.

Hinsichtlich der Streptokokken-Immunität wurden analoge Anschauungen vertreten und auch hier sowohl Antitoxin wie balitericide Kräfte supponirt, ohne dass eine Einigung der Anschauungen zu Stande gekommen wäre. Noch mehr aber als bei den Pneumokokken wurde auf die cellulären Vorgänge Gewicht gelegt: insbesondere hat Bordet ${ }^{8}$ auf Grund ausgedehnter Versuche die immunisirende Wirkung des Serums ausschliesslich auf Phagocytose zurūckgeführt. Bereits vorher waren jedoch dureh Denys in Gemeinschaft mit seinen Schülern Leclef und Marchand ${ }^{9}$ die phagocytären Vorgänge, die sich bei der Immunität gegen Streptokokken abspielen, beschrieben und durch eine ganz neuartige Methodik näher analysirt worden: diese Beobachtungen haben dann den Ausgangspunkt für unsere Untersuchungen abgegeben.

Auch die Mehrzahl der späteren Beobachter hat sich der Ansicht genähert, dass man zur Erklärung der Streptokokkenimmunität ohne die Annahme der Mitwirkung cellulärer Einflüsse nicht auskommt. Wir verweisen insbesondere auf die Ausführungen über die Theorie der Wirkung des Streptokokkenserums von Aronson ${ }^{10}$, Meyer ${ }^{11}$, Michaelis ${ }^{12}$,

1 Diese Zeitschrift. 1894. Bd. XVI. S. 412.

${ }^{2}$ Riforma medica. 1891.

8 Archiv für Ophthalmologie. 1902.

- Kolle-Wassermann's Handbuch der path. Mikroorganismen. Bd. IV.

5 Annales de l'Institut Pasteur. 1893.

- Diese Zeitschrift. Bd. XXV.

7 Berliner klin. Wochenschrift. 1903. S. 358.

8 Annales de l'Institut Pasteur. 1897.

- La cellule. 1895. - Bull. de l'Acad. r. de Belgique. 1896.

${ }^{10}$ Berliner Klin. Woehenschrift. 1902. Nr. 42. - 1903. S. 399. - Deutsche med. Wochenschrift. 1903. Nr. 25.

11 Zeitschrift für klin. Medicin. 1903. Bd. L.

12 Verein für innere Medicin. 16. III. 1903. 
v. Lingelsheim. ${ }^{1}$ Die Ansichten dieser Autoren stimmen insoweit überein, als sie zu dem Schlusse kommen, dass das Streptokokkenserum zum Mindesten nicht völlig in das Schema der baktericiden Sera hineinpasst und dass zweifellos celluläre Vorgänge eine gewisse Rolle darin spielen. Zu einer befriedigenden Erklärung des Mechanismus der Streptokokkenimmunität sind unserer Ansicht nach die genannten Autoren nicht gelangt; wir möchten wegen der Einzelheiten auf die angeführten Arbeiten verweisen und nur das eine hervorheben, dass darin nirgends eine weitere Ausbildung der von Denys und Leclef angegebenen Reagensglasversuche unternommen worden ist.

Die Anschauungen über die Wirkungsweise des Strepto- und Pneumokokkenserums und anderer ihnen offenbar nahestehenden Sera, wozu wir, ohne deshalb eine vollständige Uebereinstimmung in dem Mechanismus der Immunität anzunehmen, vor Allem wohl das Pest-, Rothlauf- und Milzbrandserum rechnen dürfen, haben übrigens nicht ausschliesslich ein theoretisches Interesse. Bei allen diesen Serumarten fiel es auf, dass man auch nicht annähernd so constante Versuchsreihen erhielt und daher auch nicht mit derselben Sicherheit den Titer des Serums bestimmen konnte, wie bei den wirklich baktericiden Seris, nämlich dem Choleraund Typhusserum. Diese Unregelmässigkeiten des Erfolges sind nun von vielen Autoren (z. B. von $\mathrm{Marx}^{2}$ für Rothlauf, von Römer ${ }^{3}$ für Pneumokokken, vgl. auch Dönitz' Artikel über die Werthbemessung der baktericiden Sera ${ }^{4}$ ) dureh den Mangel geeigneter Complemente erklärt und anch die Eventualität einer "Complementablenkung" ist in Betracht gezogen worden; dementsprechend hat man auch für diese Sera daran gedacht, durch Zufuhr fremden Complements ihre Ausnutzung zu sichern. Diese Fragen wird man in ganz anderem Lichte betrachten, wenn man nach unseren Versuchen annimmt, dass im Gegensatz z. B. zum Choleraserum beim Streptokokkenserum ein freies Complement sich überhaupt nicht bei der Serumwirkung betheiligt.

Unsere eigenen Untersuchungen begannen damit, dass wir uns durch Plattenversuche davon überzeugten, dass die ron uns von Kaninchen gewonnenen hochwirksamen Streptokokken- und Pneumokokkensera weder in frischem Zustande noch bei Zusatz ron Complement eine Abtödtung der Kokken bewirkten; ebenso wenig liess sich bei mikroskopischer Beobachtung eine Auflösung verfolgen. Es erübrigt sich, diese negativen

${ }^{1}$ Kolle-Wassermann's Handbuch. Bd. IV.

'Deutsche med. Wochenschrift. 1901.

${ }^{3}$ Archiv für Ophthalmologie. 1902.

4 Kolle-Wassermann's Handbuch. Bd. IV. S. 587-589. 
Versuche ausführlicher zu beschreiben. Wir zogen dann die Möglichkeit in Betracht, dass die gesuchten Complemente nicht frei im Blute, sondern in den Organen vorhanden sein könnten; einige Versuche mit Verreibungen von Milz und Leber führten jedoch zu keinem positiven Ergebniss. Da auch in der Bauchhöhle von Mäusen unter der Wirkung des Immunserums sich keine extracelluläre Auflösung der Strepto- bezw. Pneumokokken, dagegen aber eine ganz zweifellose Aufnahme durch Phagocyten zeigte, so bedienten wir uns der Versuchsanordnung, die Denys in Gemeinschaft mit Leclef für Streptokokken, später Denys Schüler Mennes für Pneumokokken angegeben hat, indem wir die Strepto- bezw. Pneumokokken im Reagensglase mit Leukocyten zusammenbrachten und theils das zugehörige Immunserum, theils normales Serum hinzufügten. Die Versuche von Mennes hat Huber ${ }^{1}$ bestätigt unter Verwendung menschlicher Leukocyten; er machte dabei die interessante Beobachtung, dass auch in normalem Serum Phagocytose stattfand, aber nur gegenüber avirulenten Pneumokokken.

Die Resultate, die wir mit dieser von Denys und Leclef geschaffenen Methodik, die uns einen sehr wesentlichen Fortschritt zu bedeuten scheint, erzielten, haben wir in unserer Eingangs citirten ersten Veröffentlichung mitgetheilt; sie seien hier nochmals kurz zusammengefasst.

1. Konnten wir das Denys-Leclef'sche Phänomen, nämlich das Zustandekommen einer äusserst lebhaften Phagocytose im Reagensglase, beim Zusammentreffen von Leukocyten, Kokken und dem zugehörigen Immunserum bestätigen, ebenso das Ausbleiben des Phänomens in den Controlen mit normalem Serum.

2. Konnten wir durch den Bindungsversuch den Nachweis führen, dass das Serum nicht auf die Leukocyten, sondern die Kokken verändernd einwirkt; nur diese fixiren das specifische Agens.

3. Bei dem ganzen Phänomen spielen die Complemente des Serums keine Rolle.

4. Die Veränderung, durch welche die Kokken zur Aufnahme in die Phagocyten geeignet gemacht werden, ist eine specifische, eine Schädigung irgend welcher Art oder Abtödtung genügt dazu nicht; auch abgetödtete Kokken wurden erst dann aufgenommen, wenn specifisches Serum zugesetzt wurde.

Diese Anschauungen bedeuten unseres Erachtens in der Hauptsache eine Anerkennung der Metschnikoff'schen Phagocytentheorie, insofern sie überhaupt der Phagocytose die ausschlaggebende Rolle bei der Immu-

'Berliner klin. Wochenschrift. 1903. S. 358. 
nität gegenüber den beiden in Rede stehenden Wikroorganismen zuerkennen. Andererseits aber stehen sie in Bezug auf die Erklärung über das Zustandekommen der Phagocytose in wichtigen Punkten im Gegensatz zu den Lehren der Metschnikoff'schen Schule. Auf diese Differenzpunkte wollen wir nunmehr näher eingehen.

Denys und Leclef hatten bereits nachgewiesen, dass sich die Leukocyten eines immunen Thieres an sich nicht anders wie die eines normalen verhalten; wenn sie trotzdem eine lebhafte Phagocytose ausüben, so erhalten sie diese Fähigkeit erst durch das Serum. Metschnik off ${ }^{1}$ hat die Beweiskraft dieser Versuche mit der Begründung bekämpft, dass dabei ,die Phagocytose in einer von den natürlichen Bedingungen zu sehr abweichenden Form auftritt, als dass man aus derselben irgendwelche Schlüsse zu ziehen berechtigt wäre".

Dies ist unserer Ansicht nach für die vorliegenden Versuche unzutreffend. Wenn etwa die isolirten Leukocyten im Reagensglase überhaupt nicht im Stande wären, z. B. Streptokokken in sich aufzunehmen, so brauchte das natürlich nicht maassgebend für die Vorgänge im Körper zu sein; wir könnten dann eben annehmen, dass sie in Folge ihrer Isolirung aus dem lebenden Organismus die Fähigkeit zur Phagocytose verloren hätten. Ganz anders liegt die Sache aber bei positivem Ausfall des Experimentes. Wir sehen, dass die Leukocyten in vitro eine ebenso intensive und durchaus ebenso verlaufende Phagocytose wie im Thierkörper entfalten können, dass diese Phagocytose aber nur in Gegenwart von specifischem Serum eintritt, gleichriel ob die Lenkocyten von einem immunen oder einem normalen Thier stammen. Hiernach scheint uns der Schluss unabweisbar, dass auch die Phagocytose, die wir im Körper des immunen Thieres beobachten, während sie beim normalen fehlt, nicht auf einer erworbenen Veränderung der Leukocyten, sondern des Serums beruht.

Dieser Standpunkt ist unvereinbar mit der Auffassung, dass die Leukocyten eines immunisirten Thieres dazu ,erzogen" seien, die Bakterien anzugreifen. Noch in seiner Monographie ${ }^{2}$ spricht sich Metschnikoff in diesem Sinne aus und sagt speciell mit Bezug auf die erworbene Immunität gegen Milzbrand: „Der grundlegende Unterschied ist auf die Empfindlichkeit der Leukocyten zurückzuführen; diese zeigen beim normalen Kaninchen negative, beim immunisirten positive Chemotaxis gegenüber dem betreffenden Krankheitserreger." Dem gegenüber bedeutet der Standpunkt von Denys gewissermaassen bereits eine Annäherung an die "humorale" Theorie.

${ }^{1}$ Immunität bei Infectionskrankheiten. Deutsche Ausgabe. S. 252.

2 A. a. O. S. 193. 
Immerhin stimmen Denys und seine Schüler mit Metschnikoff darin überein, dass auch sie eine stimulirende Wirkung des specischen Serums auf die Leukocyten annehmen. Diese Vorstellung ist von Metschnik off und seinen Schülern an zahlreichen Stellen vertreten und allen Einwänden gegenüber verteidigt worden. Metschnik off ${ }^{1}$ selbst führt aus, dass die Immunsera nicht nur auf die Bakterien, sondern „unmittelbar auf den inficirten Organismus einwirken, indem sie seine Schutzapparate zur stärkeren Bethätigung anregen". Die Wirkung des Hog-Choleraserums erklärte er damit, „dass dies die Bakterien in keiner Weise beeinflussende Serum seine Wirkung allein auf den Organismus des passiv immunisirten Thieres ausübt," und dass es „die Phagocyten gegen die Toxine weniger empfindlich macht und zu energischem Kampfe gegen die Bakterien stimulirt". Bezüglich der Streptokokken-Immunität sagt Metschnikoff, dass ,die durch das Immunserum zu erhöhter Thätigkeit angespornten Phagocyten einen wesentlichen Antheil daran haben". Metschnikoff's Anhänger und Schüler haben in demselben Sinne die Annahme von Stimulinen vertreten; es sei nur auf die bekannten Arbeiten von Bordet, Mesnil, Besredka, Gengou hingewiesen. Mesnil ${ }^{2}$ fasst seine Resultate über die Wirkung des Rothlaufserums dahin zusammen: Die Wirkung des Serums besteht in einer Stimulirung der Phagocyten. Das Serum ist also ein Excitans für die Zellen, die mit der Vertheidigung des Organismus betraut sind. In einer Arbeit, die aus Metschnik off's Laboratorium im vorigen Jahre während der Drucklegung unserer ersten Mittheilung erschien, beschäftigt sich Besredka ${ }^{3}$ eingehend mit der Wirkungsweise des Antistreptokokkenserums und kommt dabei zu folgenden, den unserigen entgegengesetzten Anschanungen: „Das Serum übt keine directe Wirkung auf die Streptokokken aus.... Es bleibt also nur eine einzige Interpretation als möglich übrig, ... dass nämlich das Ueberleben der mit Serum behandelten Thiere auf der stimulirenden Wirkung beruht, welche das Serum auf die weissen Blutkörperchen ausübt.":

Entsprechend dieser Auffassung über die Stimuline haben Metschnik off und Besred ka weiterhin die Annahme vertreten, dass man durch Injection von stimulinhaltigem Serum bei einem anderen Thiere wiederum ein ,antiphagocytäres Serum" erhalten könne.

Wir glauben, dass sich die Annahme von Stimulinen nicht länger aufrecht erhalten lässt, und halten uns für berechtigt, in diesem einem Punkte

1 A. a. O. Cap. VIII-X.

2 Annales de l'Institut Pasteur. 1899. T. XIII.

- Ebenda. 1904.

Ebenda. 1901. T. XV. 
die von uns für Streptokokken und Pneumokokken erhaltenen unzweideutigen Ergebnisse als allgemeingültige auf die analogen Verhältnisse bei anderen Mikroorganismen zu übertragen.

Durch den von uns angestellten Bindungsversuch ist nachgewiesen, dass das Serum eine specifische Bindung mit den Bakterien eingeht, aber nicht mit den Leukocyten; es ist also kein "Stimulans" oder ,Excitans" für die Zellen, sondern bewirkt eine eigenthümliche Umwandlung der Bakterien. Um diese neugewonnene Anschaung durch einen sinnentsprechenden Namen zu präcisiren, möchten wir die Sera, die den Gegenstand unserer Untersuchungen bilden, als "bakteriotrope“ im Gegensatz zu den bakteriolytischen bezeichnen. Der Name besagt nichts weiter, als dass unter dem Einfluss des Serums eine Umwandlung oder Umstimmung der Bakterien stattfindet, als deren Ausdruck wir zunächst nur ihr verändertes Verhalten den Leukocyten gegenüber kennen. Es ist jedoch möglich, dass die Bedentung dieser Stoffe hiermit nicht erschöpft ist und dass beispielsweise in den inneren Organen noch andere mit der Immunität zusammenhängende Vorgänge sich abspielen; gerade deshalb schien uns ein so allgemein gehaltener Ausdruck zweckmässig. Dass die bakteriotropen Stoffe des Serums etwa mit den Agglutininen identisch sein sollten, war a priori sehr unwahrscheinlich. Direct ausschliessen können wir diese Möglichkeit, nachdem wir zufällig von einem Kaninchen ein Serum erhalten haben, das auf Streptokokken stark bakteriotrop, aber gar nicht agglutinirend wirkte. Ueber das Verhältniss der bakteriotropen zu den bakteriolytischen Stoffen können wir aus den Untersuchungen mit Strepto- und Pneumokokken keine Anhaltspunkte gewinnen, da uns hier keine specifischen Lysine begegnet sind. Diese Frage ist in einer vor Kurzem erschienenen Arbeit von Neufeld und Töpfer ${ }^{l}$ behandelt und dahin entschieden worden, dass beide Arten von Stoffen nicht identisch sind. Gerade dieser Nachweis hat uns die Veranlassung gegeben, die bakteriotropen Stoffe nunmehr mit einem eigenen Namen zu belegen.

Wir möchten in diesem Zusammenhange bemerken, dass wir absichtlich nicht die interessanten Befunde von Radziewski² und die von ihm angewandten Färbungsmethoden für unsere Zwecke herangezogen haben. Dieser Autor hat gefunden, dass im Verlauf der Infection mit verschiedenen Bakterien, unter anderen auch mit Pneumokokken, neben der enormen Vermehrung der Bakterien stets, auch bei hochempfindlichen Thieren, eine fortdauernde Abtödtung und Auflösung derselben einhergeht, die sich

${ }^{1}$ Centralblatt für Bakteriologie. 1905. Nr. 5.

2 Diese Zeitschrift. Bd. XXXVII. 
durch besondere Färbemethoden darstellen lässt. Wir haben diese Vorgănge zunächst ausser Acht gelassen, da sie auch bei normalen Thieren vorkommen, während uns ausschliesslich daran gelegen war, aufzuklären, worin der Unterschied im Verlauf' der Reaction bei normalen und bei immunisirten Thieren besteht. Hier glauben wir in dem Verhalten der durch die bakteriotropen Substanzen des Serums modificirten Bakterien gegenüber den Leukocyten den bisher wenigstens einzig greif baren Unterschied gefunden zu haben.

Diese Eigenschaft fand sich dementsprechend auch bei jedem überhaupt wirksamen Serum, gleichviel welcher Herkunft. In unserer ersten Mittheilung ist nur von dem Serum eines von uns gegen einen Streptococcus immunisirten Kaninchens die Rede. Wir haben seitdem die Sera von einigen anderen in derselben Weise behandelten Kaninchen, ferner von einer mit dem gleichen Streptococcus immunisirten Ziege, sowie endlich einige Proben des von Aronson an Pferden gewonnenen Serums untersucht und bei allen die gleichen im Reagensglase ebenso wie im Thierkörper zur Wirkung gelangenden bakteriotropen Stoffe gefunden. $\mathrm{Da}$ das Aronson'sche Serum durch Vorbehandlung mit einem anderen Streptococcus gewonnen ist, so geht hieraus hervor, dass sich die specifische Serumwirkung auch im Reagensglase nicht ausschliesslich gegen einen bestimmten Streptokokkenstamm richtet; dies stimmt völlig mit den früher von dem einen von uns ${ }^{1}$ mitgetheilten Versuchen überein, wonach im Thierversuch ein mit einem Streptokokkenstamm gewonnenes Serum durchaus in derselben Weise gegen jeden zum Versuch herangezogenen Stamm schützte, wie gegen den homologen.

Ebenso wie die Sera haben wir später auch die Leukocyten nicht nur von Kaninchen, sondern auch von anderen Thierarten zu den Reagensglasversuchen herangezogen. Insbesondere fanden wir die von Meerschweinchen (durch Aleuronatinjection in die Bauchhöhle) erhaltenen Leukocyten insofern sehr geeignet, als wir bei ihnen seltener als bei Kaninchen Exsudate mit schlechtbeweglichen Zellen erhielten; solche darf man aber zu diesen Versuchen nicht benutzen, sondern muss sich vorher im hängenden Tropfen von der genügenden Beweglichkeit überzeugen. Wir haben daher später meist mit Meerschweinchenleukocyten gearbeitet, ferner gelegentlich mit solchen von Mäusen und, worauf wir noch zurückkommen, mit Leukocyten, die wir aus einem ganz frischen Abscess vom Henschen gewornen hatten. Es ergab sich, dass die Herkunft der Leukocyten (sobald sie nur gut beweglich sind) auf das Denys-Leclef'sche Phänomen ebensowenig einen Einfluss hat, wie die Thierart, von der das Serum stammt, sondern

${ }^{1}$ Diese Zeilschrift. Bd.XLIV. 
dass dieses Phänomen ausschliesslich von dem Gehalt des Serums an specifischen Stoffen abhängt. Diese Thatsache spricht ganz unzweideutig dafür, dass die specifischen Wirkungen sich ausschliesslich zwischen dem Serum und den Bakterien abspielen; denn wenn daneben auch eine directe Wirkung des Serums anf die Zellen in Frage käme, so müsste man erwarten, dass z. B. ein von Kaninchen stammendes Serum die Leukocyten von Kaninchen stärker als die von anderen Thierarten beeinflussen würde, und andererseits auch stärker als ein vom Pferde oder der Ziege gewonnenes Immunserum. Bei unseren vielfach variirten Versuchen hat sich niemals etwas Derartiges ergeben; auch das scheint uns ein gewichtiger Grund gegen die Annahme einer stimulirenden Wirkung des Serums zu sein.

Indem wir uns aus den soeben dargelegten Gründen ge$z$ wungen sehen, einige von Metschnikoff und seinen Schülern eifrig verteidigte Hypothesen als nicht vereinbar mit den neu gewonnenen Thatsachen aufaugeben, bleibt dennoch unseres Erachtens der Grundgedanke der Phagocytentheorie hierron unbeeinflusst bestehen; ja, wir glauben sogar, dass diese Theorie in der von uns (zunächst für die Immunität bei zwei bestimmten Bakterienarten) gegebenen Modification sich manche neuen Anhänger erwerben dürfte. Einer der Hauptgründe, die im Besonderen in Deutschland die Phagocytentheorie zu keiner allgemeinen Anerkennung kommen liessen, war unserer Ansicht nach - neben der zu weit gehenden Verallgemeinerung derselben auf nahezu alle Verhältnisse der natürlichen und künstlichen Immunität - ihre Unvereinbarkeit mit den Grundgedanken (nicht etwa nur mit gewissen Einzelheiten) der Ehrlich'schen Theorie. Dieser Theorie zu Folge muss der Bestandtheil des Serums, welcher der Träger der specifischen Wirkung ist, eine exclusive Beziehung zu dem Stoffe haben, der zur Immunisirung gedient hat: das Antitoxin zum Toxin, das Hämolysin zum Erythrocyten, die baktericide oder agglutinirende Substanz zum Bacterium. Diese Exclusivität ist allerdings, ihrem eigentlichen Sinne entsprechend, etwas weiter zu fassen, indem sie sich bisweilen auch auf andere Zellen oder andere gelöste Stoffe, als diejenigen, mit denen das betreffende Thier immunisirt worden ist, erstrecken kann, insoweit jene nämlich gemeinsame Receptoren mit den letzteren haben; aber als völlig unvereinbar hiermit müssen wir die Vorstellung ron "Stimulinen" ansehen, wonach bei einem mit Streptokokken oder Pneumokokken vorbehandelten Thiere Stoffe in's Blut abgestossen werden sollen, die eine specifische Wirkung auf die Phagocyten des Kaninchens, der Maus und anderen Thierarten haben. Diese Differenz zwischen den Theorieen Ehrlich's und Metschnik off's würde durch die von uns gegebene Erklärung aus der Welt geschafft werden. 
Was die eigentliche Wirkungsweise der bakteriotropen Stoffe anlangt, so bleibt da noch viel zu erklären übrig. Die naheliegende Vermuthung, dass etwa zuerst eine extracelluläre Abtödtung der Bakterien und dann erst secundār die Aufnahme durch: die Phagocyten erfolgt, ist, wie wir in unserer ersten Wittheilung bereits nachgewiesen haben, nicht haltbar. Man konnte ferner an die Möglichkeit denken, dass durch das Serum gewisse, von den virulenten Kokken ausgeschiedene Stoffe, durch welche diese sich vor den Phagocyten schützen, neutralisirt würden; in dieser Weise ist ja öfters die Thatsache, dass die Phagocyten sich von den virulenten Kokken fern halten, erklärt worden. Eine solche Auffassung hätte die Wirkung des Serums in gewissem Sinne als eine antitoxische erscheinen lassen. Hiergegen spricht aber $u$. a. schon die mitgetheilte Beobachtung, dass auch abgetödtete Kokken, die doch keine derartigen Stoffe mehr secerniren können, ebenfalls erst durch das Serum zur Aufnahme in die Leukocyten präparirt werden.

Ernstlicher haben wir dagegen die Vorstellung in Betracht gezogen, dass die Wirkung des Serums darauf beruht, dass durch dasselbe gewisse feste Receptoren der Bakterienzelle, die auch bei der Abtödtung erhalten bleiben, und zwar diejenigen Receptoren, welche die Träger der Virulenz des betreffenden Bacteriums sind, besetzt und dadurch ausser Funetion gesetzt werden. Die Vorstellung, dass die Virulenz eines Bacteriums auf dem Besitz ron bestimmten Receptoren bezw. von besonders zahlreichen Receptoren einer bestimmten Art beruht, ist. insbesondere von Pfeiffer näher begründet worden. Bekanntlich sind nun gerade bei den Streptokokken und Pneumokokken die Schwankungen der Virulenz im. Vergleich z. B. mit den Typhusbacillen ganz ungeheure; wir kennen Stämme, von denen der millionste Theil eines Cubikcentimeters Mâuse und Kaninchen mit Sicherheit tödtet und andere, von denen ein ganzer Cubikcentimeter unschädlich ist: ja derselbe Stamm kann im Verlauf einer kurzen Fortzüchtung sim Laboratorium von dem einen zum anderen Extrem schwanken. Im Gegensatz zu anderen Bakterien, bei denen wir' stark wirksame Gifte entweder in den Seeretionsproducten oder in der Leibessubstanz nachweisen können, wirken ja die „SepticämieErreger", zu denen die beiden hier in Rede stehenden Kokkenarten in exquisitem Maasse gehören, vorzugsweise durch ihre Virulenz deletär, d. h. durch ihre Fähigkeit, sich im Blute und in den Organen des Körpers scheinbar schrankenlos zu vermehren. Wenn wir nun annehmen würden, dass durch das Immunserum geride diejenigen Receptoren ausser Function gesetzt werden, welche die Virulenz des Pneumo- oder Streptococeus bedingen, so würde das als eine im höchsten Grade zweckmässige Ein- 
richtung erscheinen: es würde dabei diesen Bakterien die Waffe, mit der sie den Körper bedrohen, ebenso sicher entwunden werden, wie dem Diphtherie- oder dem Tetanusbacillus, dessen Toxin neutralisirt wird.

In Consequenz dieser Vorstellung müssten wir erwarten, dass, wenn das Serum speciell an die die Virulenz bedingenden Receptoren des Bacteriums gebunden wird, es eben diese Receptoren sind, die die Production der Immunstoffe bezw. deren Abstossung in die Blutbahn auslösen. Dann müssten also avirulente Kokken unfähig sein, die Immunkörperbildung auszulösen, abgetödtete virulente Kokken dagegen (nach dem oben Gesagten) fähig dazu. Diese Annahme scheint mit den bisher bekannten Thatsachen übereinzustimmen. Wie in den früheren Arbeiten des Einen von uns mitgetheilt ist, gelingt es sowohl bei Pneumo- als bei Streptokokken durch eine einmalige Injection der abgetödteten Körpersubstanz von virulenten Kokken eine relativ hohe Immunität zu erzielen. Was dagegen die immunisirende Wirkung avirulenter Culturen anlangt, so stand damals ein ganz avirulenter Pneumokokkenstamm zur Verfügung, von dem selbst $10.0 \mathrm{~cm}$ lebender Cultur Kaninchen nicht tödteten: eine Immunität gegen einen virulenten Stamm wurde durch ihn aber nicht erzengt. Aehnliche Beobachtungen wurden in der Folge noch mehrmals gemacht; es scheint also bei Pneumokokken in der That eine Immunisirung durch gänzlich arirulente Stämme nicht zu gelingen. Bezüglich der Streptokokken wurde zwar nicht der gleiche Versuch gemacht, dagegen durch Untersuchung des Moser'schen Streptokokkenserums (von Pferden stammend) festgestellt, dass dieser avirulente Stamm keine Bildung von Schutzstoffen auslöste. ${ }^{1}$ Der von Moser zur Immunisirung benutzte Streptokokkenstamm erwies sich nāmlich als völlig avirulent, und dementsprechend hatte das mit demselben erzeugte Serum keine immunisirende Wirkung; dagegen besass es hohe Agglutinationskraft gegenüber allen, auch höchstvirulenten Streptokokkenstämmen, wobei den verschiedenen Stämmen bezw. den verschiedenen Modificationen derselben Stämme gegenüber durchaus die gleichen Schwankungen sich zeigten, wie bei agglutinirendem Serum, das durch Vorbehandlung mit unseren hochvirulenten Streptokokken erzengt war. ${ }^{2}$ Der Moser'sche Streptococcus hatte also eine Reihe von Receptoren, darunter solche, die bei der Agglu-

1 Diese Zeitschrift. Bd. XLIV.

2 Da ich meine damaligen Ausführungen mehrfach so citirt finde, als führte ich die Schwankungen bei der Agglutination der Streptokokken ausschliesslich auf Veränderungen der Virulenz zurück, so möchte ich hier nochmals betonen, dass Ineiner Erfahrung nach beide Erscheinungen zwar häufig, jedoch durchans nieht regelmässig und vollständig mit einander parallel gehen.

N. 
tination in Function treten, mit unseren Stämmen gemeinsam, nur fehlten diejenigen, auf denen die Virulenz beruht. ${ }^{1}$

Die soeben mitgetheilten Erfahrungen weisen darauf hin, dass die bakteriotropen Stoffe des Serums in enger Beziehung zu den Receptoren der Bakterienzelle stehen, auf denen die Virulenz beruht, und dass sie ein Reactionsproduct des inficirten Organismus auf eben diese Receptoren sind.

In unserer ersten Mittheilung batten wir die Frage offen lassen müssen, ob die Bedeutung der bakteriotropen Substanzen sich darin erschōpft, die Aufnahme der Bakterien in die Phagocyten zu vermitteln, oder ob sie auch an der intracellulären Verdauung der Bakterien betheiligt sind und hierbei etwa die Rolle eines Amboceptors spielen, zu dem im Innern des Leukocyten ein passendes Complement tritt. Cm diese Frage zu lösen, haben wir uns bemüht, die zweifellos in den Leukocyten vorhandenen wirksamen Stoffe zu extrahiren. Wir haben dazu die Mlaceration bei $3^{\circ}$,

1 Hier ist natürlich zunächst von der Virulenz für die Laboratoriumsthiere und von der Wirkung des Serums im Thierversuch die Rede. Ich möchte aber bei dieser Gelegenheit eine in nexerer Zeit mehrfach geäusserte Anschauung über das Verhältniss der Thier- und der Menschenpathogenität nicht unwidersprochen lassen. Koch and Petruschky (diese Zeitschrift, Bd. XXIII) haben durch Impfungen an Menschen gezeigt, dass der ron Marmorek zur Serumgewinnung benutzte Streptococcus für Menschen gar nicht pathogen war. Dieser Streptococcus stammte von der Oberfläche der Tonsille eines an Angina Erkrankten und war durch Kaninchenpassagen zu hoher Virulenz für Kaninchen herangezüchtet worden; wir müssen hieraus schliessen, dass durch solche Passagen ein Streptococcus nicht gleichzeitig für Menschen virulent wird. Eine weitere Beobachtung derselben Autoren spricht dafür, dass Kaninchenpassagen nicht einmal ein sicheres Mittel sind, einem ursprünglich für Menschen virulenten Streptococcus diese Virulenz za erhalten.

Die Anschaung aber, dass nun umgekehrt ein Streptococcus dadurch für Menschen virulent erhalten werden sollte, dass man ihn in einer Weise aufbewahrt, bezw. fortzüchtet, die seine Virulenz für Mäuse and Kaninchen völlig verloren gehen lässt, - diese Anschauung stützt sich auf keine einzige Thatsache und darf wohl als ausserordentlich unwahrscheinlich bezeichnet werden. Für durchans unriebtig möuhte ich nach meinen Erfahrungen die vielfach (neuerdings auch von Aronson) vertretene Ansicht halten, dass die für Menschen pathogenen Streptokokken in der Regel von vorneherein für unsere Versuchsthiere wenig virulent seien. Das Gegentheil geht schon aus den ersten Untersuchungen Petruschky's hervor, dessen Methode zum Nachweis der Streptokokken im menschlichen Blut ja gerade anf der Thatsache beruht, dass die bei Sepsis im Blute eirenlirenden Kokken in der Regel maximale Virulenz für Mäuse besitzen. Ich habe früher sehr vielfach Gelegenheit gehabt, selbst am Krankenbett oder aus der Leiche, insbesondere bei Erysipel nnd schwerer Sepsis Streptokokken zu ziichten and sofort in der ersten oder zweiten Generation an Thieren zn prüfen; ich fand dieselben in der Mehrzahl der Fälle ganz hochvirulent für Kaninchen und Mäuse. Die gegentheiligen Beobachtungen erkläre ich mir daraus, dass die Virnlenz der Streptokokken, wenn sie frisch aus dem Menschenkörper kommen, eine noch viel labilere ist, als wenn sie bereits längere Zeit im Laboratorium gezüchtet 
die Extraction mit inactivem Serum fremder Thierarten, ferner wiederholtes Gefrieren und Aufthauen angewandt, - Methoden, welche sich zur Extraction von "Alexinen" aus den Zellen bewährt haben. Als diese uns nicht zum Ziele führten, machten wir einige Versuche mit ,leukotoxischem" Serum, das wir uns durch Vorbehandlung ron Meerschweinchen mit leukocytenhaltigem Material von Kaninchen herstellten. Keine dieser Methoden führte uns zum Ziel; d. h. es gelang uns auf keine Weise, aus den Leukocyten Stoffe in Lösung zu erhalten, die, sei es für sich allein, sei es nach Hinzufügung des "Immunkörpers" in Gestalt specifischen Serums, unsere virulenten Strepto- und Pneumokokken aufzulösen im Stande waren. Dass man durch die genannten Methoden beträchtliche Mengen von „Alexinen" aus den Leukocyten gewinnen kann, die gegenüber einer Reihe von Mikroorganismen wirksam sind, ist durch zahlreiche Versuche verschiedener Autoren er-

sind; es genügt dann schon eine kurze Fortzüchtung auf ungeeignetem Nährboden, um sie schnell sinken zu lassen. Kaninchen und Mänse sind im Allgemeinen wohl empfänglicher für Streptokokken als der Mensoh und wenn die menschenpathogenen Streptokokken in der Regel für diese Versuchsthiere erst recht virnlent sind, so spricht die Wahrscheinlichkeit dafür, dass diejenigen Stämme, die ihre Virulenz für Kaninchen und Mäuse völlig verloren haben, auch für Menschen nicht mehr virulent sind.

Wenn ich es also für wahrscheinlich halte, dass die für Thiere avirulent gewordenen Streptokokken auch nicht mehr menschenpathogen sind, so ist die Möglichkeit, dass diese letztere Eigenschaft anch durch wiederholte Thierpassagen beeinträchtigt wird, ebensowenig anszuschliessen. Koch and Petruschky warnen in ihrer sitirten Arbeit vor der Anwendung derartiger, durch vielfache Passagen angegezüchteter Culturen zur Serumgewinnung. Sie sagen: „Nach diesen Erfabrungen muss es sehr fraglich erscheinen, ob es überhaupt ein richtiger Gedanke war, mit derartigen Streptokokken, die für den Menschen ganz unschädlich sind, die Erzeugung eines Antistreptokokkenserums zu versuchen, welches doch gegen die dem Menschen schädlichen Streptokokken in's Feld geführt werden sollte. Sowohl Marmorek wie A ronson haben derartige Streptokokken zur Erzeugung ihres Serums verwendet, ausgehend von dem Gedanken, höchstvirulente Streptokokken an sich in Händen zu haben.“

Später haben Tavel, Moser u. A. den hier ausgesprochenen Gedanken aufgenommen; aber die Art, wie sie ihn in die Praxis umgesetzt haben, möchte ich nicht als zweckmässig ansehen. Petruschky hat seiner Zeit die zu den Impfungen am Menschen bestimmten Streptokokken nicht durch Thierpassagen virulent erhalten, sondern durch die von ihm als ausgezeichnet zur Erhaltung der Virulenz gefundene Methode der Aufbewahrung im Gelatinestich bei Eisschranktemperatur. Da wir wissen, dass die so aufbewahrten Culturen Monate lang für Thiere hochvirulent bleiben, șo dürfen wir vermuthen, dass auch die Virulenz für den Menschen sich dabei erhält; in der That wurde diese Voraussetzung durch den Ausfall der da. maligen Erysipelimpfungen an Carcinomkranken bestätigt. Wenn man also auf die Vermeidung aller Thierpassagen einen so hohen Werth legt, so wäre es gewiss rationell, nach derselben Yethode die Streptokokkenstämme zu conserviren, mit denen man ein Serum zur Anwendung an Menschen gewinnen will. Neufeld. 
wiesen; offenbar sind also diese "Alexine" mit den Stoffen, die in unseren Versuchen die intracellulare Auflösung der Bakterien bewirken, nicht identisch.

$\mathrm{Da}$ es uns also nicht gelungen ist, die Auflösung der Kokken ausserhalb der Leukocyten vor sich gehen zu lassen, so können wir die Frage, auf welchen Stoffen dieselbe beruht und ob dabei, ebenso wie bei der Bakteriolyse durch specifisches oder normales Serum, ein Zusammenwirken von zwei Substanzen stattfindet, nicht entscheiden.

Zur Ergänzung unserer früheren Mittheilung seien noch folgende einzelne Punkte' hervorgehoben.

Was die quantitativen Verhältnisse anlangt, so schien uns die Stärke der im Reagensglase gemessenen bakteriotropen Wirkung eines Serums mit der Schutzwirkung an Mäusen parallel zu gehen. Bei einem stark wirksamen Kaninchenserum stellten wir die quantitativen Verhältnisse dahin fest, dass 0.2 davon eine Maus in der Regel bis gegen 0.1 , zuweilen auch noch gegen 0.2 der 24 Stunden nach der Serumapplication injicirten Bouilloncultur unseres hochvirulenten Streptococcus schützte: von demselben Serum löste noch 0.003, im Reagensglase mit 0.2 Leukocytenaufsehwemmung und 0.2 Streptokokkenhouilloncultur gemischt, eine recht lebhafte Phagocytose aus, während 0.001 keinen deutlichen Effect mehr hatte.

Eine auffallende noch nicht erwähnt $\$$ wurde, ist die Neigung derjenigen Lenkocyten, welche mit Kokken gefüllt sind, sich in grossen, festen Haufen zusammenzuballen; schon hierdurch bekommen die aus den mit Immunserum versetzten Röhrchen angefertigten Präparate ein ganz anderes Aussehen als die aus den Controlröhrchen. Diese intensive Haufenbildung ist eine secundäre; sie bleibt aus, wenn man die Leukocyten allein mit dem Immunserum versetzt, ohne die Kokken hinzuzufügen. Ebenso auffallend ist - insbesondere bei der Infection mit Pneumokokken - die Verklumpung der Leukocyten in der Bauchhöhle von immunisirten Mäusen während des Actes der Phagocytose. Levaditi' ${ }^{1}$ hat bei der Spirochätenkrankheit des Huhnes einen ähnlichen Vorgang im Thierkörper unter der Wirkung des Immunserums beschrieben; er führt denselben auf eine unmittelbare Wirkung des Serums auf die Leukocyten des branken Thieres zurück.

Als sehr bequem erwies sich uns das Arbeiten mit carbolisirtem Serum; insbesondere bei Anwendung kleinerer Serumdosen liess der geringe Carbolgehalt keine Schädigung der Thätigkeit der Phagocyten erkennen.

1 Annales de l'Institut Pasteur. 1904. 
Dass freie Complemente bei dem ganzen Vorgange keine Rolle spielen, haben wir schon früher nachgewiesen; dementsprechend haben wir späterhin fast stets mit inactivirten, bezw. carbolisirtem Immunserum gearbeitet und die Leukocyten anstatt in Serum in Kochsalzlösung aufgeschwemmt.

In ziemlich seltenen Fällen zeigte sich auch in den Controlröhrchen, die keinen Zusatz von specifischem Serum hatten, eine lebhaftere Phagoeytose. Diese blieb jedoch aus, wenn wir die Lenkocyten mehrmals in Kochsalzlösung wuschen, so dass die Spuren der anhaftenden Exsudatflüssigkeit möglichst beseitigt wurden; wir möehten daher annehmen, dass derartige Exsudate von Meerschweinchen oder Kaninchen bisweilen bakteriotrope Substanzen gegenüber den Streptokokken enthalten können.

Von Interesse war es, festzustellen, ob auch die menschlichen Leukocyten sich den Streptokokken gegenüber ebenso verhalten, wie die von Kaninchen und Meersehweinchen. A priori schien es nicht ausgeschlossen, dass die mit den Leukocyten versehiedener Laboratoriumsthiere angestellten Versuche mit menschlichen Leukocyten nicht gelingen würden. Verhält sich der Mensch doch gerade den Streptokokken gegenüber ganz anders wie unsere Versuchsthiere. Bei diesen finden wir, sobald sie eine schwere Streptokokkeninfection überwunden haben, meist eine ganz zweifellose Immunität: sie vertragen reactionslos ein oft erhebliches Multiplum der ersten Dosis, und ihr Serum hat fast immer eine deutliche Schutzwirkung bei versehiedenen Thierspecies. Anders liegen die Verhältnisse beim Menschen: kurz nach Ablauf eines Erysipels kann durch Impfung mit demselben Streptococcus immer wieder ein Erysipel erzeugt werden ${ }^{1}$, und bei einem von einer Streptokokkenkrankheit Genesenen ist bisher noch niemais mit Sicherheit nachgewiesen worden, dass sein Serum irgendwelche Sehutzkörper enthält; wir selbst hatten bei vielfachen Versuchen dieser Art stets negative Resultate. Dazu kommt, dass nach den bisherigen Erfahrungen auch ein im Thierversuch stark wirksames Serum bei der Anwendung am Menschen nicht eine so deutliche Einwirkung auf den Krankheitsverlauf gezeigt hat, wie man es hätte erwarten sollen. Man konnte daran denken, dass diese Verschiedenheiten mit einem abweichenden Verhalten der menschlichen Leukocyten zusammenhingen, und dass aus diesem Grunde der menschliche Körper ebenso unfähig sei, die bakteriotropen Stoffe eines specifischen Thierserums auszunutzen, wie er selbst ausser Stande zu sein scheint, seinerseits unter der Einwirkung einer Streptokokkeninfection Schutzstoffe zu produciren, die bei unseren Versuchsthieren wirksam sind. Nun ist es schwer, ganz frische und lebenskräftige Leukocyten von Menschen zu erhalten. Aus diesem Grunde fielen

' Koch und Petruschky, Diese Zeitschrift. Bd. XXIII. 
wohl unsere beiden ersten Versuche mit Leukocyten, die aus einer Phlegmone und einer Osteomyelitis stammten, das Denys-Leclef'sche Phänomen zu erzeugen, ganz negativ aus. Dann erhielten wir zufällig Eiter aus einem kleinen, ganz oberflächlichen und frischen, höchstens 48 stündigem Abscess, den wir im Institut selbst ineidirten und sogleich zum Versuch benutzten; im mikroskopischen Präparat fanden sich darin keine Bakterien, culturell spärlich Streptokokken.

Die gewaschenen Leukocyten zeigten nun das Denys-Leclef'sche Phänomen in typischer Weise: nach Zusatz einer kleinen Quantität unseres Streptokokkenserums wurden die reichlich hinzugefügten Streptokokken schnell und fast vollständig phagocytirt, während in der mit normalem Kaninchenserum versetzten Controle keine Phagocytose auftrat. Uebrigens gelang der Versuch ebenso mit dem Aronson'schen Serum; theoretisch lässt sich also von diesem Gesichtspunkte aus gegen die Möglichkeit der Ausnutzung der darin enthaltenen Schutzstoffe auch im menschlichen Körper nichts einwenden.

Am Schlusse unserer ersten Mittheilung hatten wir in Aussicht gestellt, über analoge Versuche mit anderen Mikroorganismen, insbesondere mit solchen, welche septicämische Krankheiten erzeugen, zu berichten. Aus āusseren Gründen mussten wir uns aber auf ein Paar orientirender Versuche mit Rothlauf und Milzbrand beschränken, Krankheiten, von denen wir nach den bisherigen Beobachtungen (ebenso wie von der Pest) mit Sicherheit annehmen dürfen, dass die bei ihnen auftretende Immunität ebenfalls nicht oder doch höchstens nur zum kleinen Theile auf einer baktericiden Wirkung des Serums beruht. Wir fanden jedoch, dass im Reagensglase bei Rothlauf und Milzbrand nicht ohne Weiteres eine bakteriotrope Wirkung des Immunserums in derselben eindeutigen Weise, wie bei Strepto- und Pneumokokken, zu Tage tritt, sondern dass insbesondere bei Rothlaufbacillen bereits im normalen Serum lebhafte Phagocytose stattindet. Unserer Ansicht nach darf man also nicht ohne Weiteres, wenn man beim Zusammenbringen von Leukocyten, Bakterien und Serum im Reagensglase Phagocytose auftreten sieht, dieses Phänomen auf immunisirende Stoffe des betreffenden Serums beziehen, sondern dieser Zusammenhang muss für jeden Fall erst bewiesen werden.

Dies entspricht auch den im Thierkörper gemachten Beobachtungen; so ist es bei Rothlauf bereits lange bekannt, dass im Thierkörper auch bei ganz virulenten Culturen und hochempfänglichen Thieren schon ohne Einwirkung specifischen Serums eine sehr starke Phagocytose eintritt. Ebenso wissen wir, dass Tuberkelbacillen die einem Meerschweinchen in die Biuchhöhle injicirt werden, sehr energisch von Phagocyten aufgenommen werden; auch hier kann von einer Immunität nicht die Rede sein. 
Bekanntlich ist man jetzt sehr vorsichtig darin geworden, Zusammenhänge zwischen der oft enorm starken baktericiden Wirkung eines normalen Serums auf gewisse Bakterien und der natürlichen Immunität der betreffenden Thiere gegen dieselben Bakterien zu construiren. Es hat sich z. B. bei Milzbrand ergeben, dass auch eine stark baktericide Wirkung eines normalen Serums absolut nicht der Ausdruck einer entsprechenden Immunität $\mathbf{z u}$ sein braucht. Eine ähnliche Zurückhaltung dürfte sich auch gegenüber der bakteriotropen Serumwirkung empfehlen.

Im Vorstehenden haben wir uns darauf beschränkt, die Stoffe zu untersuchen, auf denen unserer Ansicht nach die specifische Wirkung gewisser Immunsera beruht. Wir gehen deshalb nicht des Näheren auf die Untersuchungen von Wright ein, welcher in mehreren Arbeiten ${ }^{1}$ eine phagocytosebefördernde, von ihm als „opsonisch“ bezeichnete Wirkung normalen menschlichen Serums auf verschiedene Mikroorganismen beschrieben hat, die er als Ausdruck der Immunität ansieht. In einigen Fällen erfuhr diese „opsonische“ Serumwirkung eine gewisse Steigerung, nachdem die Versuchspersonen mit abgetödteten Culturen des betreffenden Mikroorganismus injicirt worden waren. Ob das "opsonische" Serum eine immunisirende Wirkung besass, hat Wright nicht untersucht. Des Weiteren beruht die von ihm beobachtete Serumwirkung im Gegensatz zu unseren bakteriotropen Stoffen auf einer thermolabilen Substanz.

${ }^{1}$ Die Litteraturangaben s. in Deutsche med. Wochenschrift. 1904. S. 1929. 